\title{
Research on Reasons and Countermeasures of Practice Lack for Railway Electrical Engineering Academic Graduate
}

\author{
Xiangzheng Xu \\ Department of Electronics Engineering, East China Jiao-tong University, Nanchang 330013, China
}

\begin{abstract}
This paper expounds the present situation of talent and the demand for high-level talents in the railway industry, analysis the reasons for the railway electrical engineering academic graduate students on the lack of academic training. Through field investigation and learning from the training related academic research and related graduate school experience and according to the characteristics of railway electrical engineering major, put forward the reform idea of improving academic graduate student academic level. To further optimize the mechanism of graduate student training, training mode, curriculum and teaching staff, can greatly increase the railway electrical graduate student's academic level. Thus, it can be improved the overall quality of postgraduate training to meet the requirements of the development of the railroad industry and the society.
\end{abstract}

KEYWORD: Graduate education; Academic graduate; Education reform

\section{INTRODUCTION}

Enter the twenty-first century, mankind has made great progress in technical field of knowledge indicates that the most important factor in the development of science and technology is in the process of human creativity. Postgraduate education is an important part of higher education and one of its main tasks is to cultivate students' scientific research ability (Liu Yuenan. 2014). The cultivation of this ability is to go through certain courses and through a series of systematic scientific research ability training. Therefore, how to set up the reasonable training mode and the specific training thought in the scheme the cultivation of postgraduates, research to improve our students' ability of scientific research and enhance the international competitiveness of graduate students is essential.

Academic graduate training model produced in the German, and is used in American and most of the domestic institutions of higher learning. In recent years, the graduate students of our school have been greatly expanded scale. How to ensure the quality of graduate education has been become the problems to be solved in current. Our school is mainly for the railway industry to provide the high quality and high level talent for the railway industry, continue to meet the rapid development of China's railway demand for talent. So we continue to find out the shortage of training graduate students to optimize the talent.

\section{THE TRAINING PROBLEMS OF ACADEMIC GRADUATE FOR ELECTRICAL RAILWAY}

In our school electrical engineering academic graduate culturing had achieved remarkable results, but the graduate innovation ability is still insufficient. Dig the training problems and shortcomings of the research on the academic school students for us to further improve the academic graduate training and enhance academic research has the vital significance of quality cultivation.

Our school admission way is unreasonable, "high quality of students is the basis of top-notch innovative talents", the enrollment way is not perfect weakens the basis of cultivating academic graduate (Mercedes et al. 2012). Excluding very promising students of the general university, the high-level creative talents selection source should be enlarged.

In the curriculum, teaching and learning mode is relatively simple. It plays an important role in training curriculum teaching and learning methods to students on the academic innovation ability. From the teaching mode, the current leading model of "cramming" teaching is still teaching mode and classroom interaction degree is not high (Zhu Min. 2014). The course content of frontier, innovative and 
creative needs to be strengthened, the theory teaching is more and the proportion of practice teaching needs to be improved. Training mechanism and training mode is not perfect and the configuration of graduate mentor is unreasonable.

The high quality of the tutor team is an important guarantee for cultivating high quality innovative talents, tutor guidance directly relates to the academic graduate training effectiveness. At present the academic school tutor guidance is still dominated by a pair of much guidance mode. Teacher study guide academic number is too many students, one for each of the guiding effect of relatively low frequency and guidance is relatively small. It is not conducive to the protection of the quality of graduate academic type.

Originality is the source of all the creativity and it is the core of scientific research and innovation ability. Culture originality academic graduate students are more security training priority among priorities quality of graduate students. The relative lack of academic graduate students engaged in research opportunities and quantity. It is engaged in the high level, high quality research projected by relatively few opportunities and presided over the research less chance. Choice of basic research postgraduate academic degree thesis type is not much. The frontier research emerging interdisciplinary field is less (Xiuzhen Guo. 2012). Thesis independently ability is not high and the ability to ascend. Our school has many teachers lack of projects, so as to study many academic students academic ability not to exercise and improve. These lead to study electrical academic students original innovation capability is not strong, scientific research achievements of high quality, high level is relatively small and difficult to the emergence of top-notch creative talents.

\section{DESIGN OF CURRICULUM REFORM FOR ELECTRICAL ENGINEERING ACADEMIC GRADUATE}

A course of study is an important factor to guarantee and improve the quality of postgraduate education. Undergraduate course began to set up some graduate primary academic course. Graduate level academic should be carried out around the class to cultivate students' ability of research and innovation. Therefore, the teacher can't read the text, he should adopt the discussion and heuristic teaching methods continue to develop the students' creative thinking. Academic graduate courses must highlight research and autonomy (She Yuanfu et al. 2013).

The study and research of interdisciplinary curriculum can broaden graduate vision and it is helpful to the study of student ability to think and study found from many disciplines and problem solving ability. Graduate academic ability of scientific research based on solid theoretical basis. Graduate education of my school should pay more attention to the learning and research method. The graduate student scientific research methods of learning attention should have reflected largely in the curriculum and the relevant research methods courses should be accounted for a considerable number. My school graduate student teaching should arrange more research experience with rich academic leaders to teach, not just to complete the task of the course. Through continuous reform course teaching, the formation of student, teacher supplemented, vivid situation of various new ideas emerge.

\section{TRAINING MECHANISM AND MODE REFORM OF RAILWAY ELECTRICAL ENGINEERING ACADEMIC GRADUATE}

Our traditional culture of railway electrification mechanism of personnel selection and production line type destroyed the postgraduate training personalized. In the training of comprehensive qualities of students, regardless of school or mentor all interested students study in the development of scientific research ability, evaluation of the ability of student is mostly based on how many research papers published, published what level the article as the judgment standard. Tutor for the actual work ability, quality and potential has not been enough attention. Electrical supervisor should be quick thinking and detailed training plan for the students.

In my school electrical engineering academic graduate academic training was absent. From the system and funding to encourage teachers to carry out school enterprise and inter school cooperation, and win more chances to participate in the project, and continuously strengthen the research of electrical school student academic practice ability. We can also and scientific research institutes to conduct joint training. This will greatly enhance our electrical graduate research level (Hong $\mathrm{Yu}$ et al. 2012). In the academic graduate requirements, we should according to the academic ability to meet graduation requirements, rather than by the time stipulated time of graduation. This will make our academic life of electric China more time and experience in scientific research instead of waiting for the graduation time.

\section{SUPERVISOR ALLOCATION REFORM OF RAILWAY ELECTRICAL ENGINEERING ACADEMIC GRADUATE}

At present, mentor configuration is too single in my school students. Tutor group joint training is benefit 
by mutual discussion embodiment and requirements, can effectively avoid the defect and deficiency of single tutor brings. Therefore, our school must be mobilized multi-disciplinary, interdisciplinary and cross school tutor group formation. Try to adopt the double tutorial system, hire business talents as the academic graduate assistant tutor, optimizing the structure of teacher team, make academic in combining theory and practice of graduate students (Yu Shuangcheng et al. 2014). Encourage academic graduate students to participate actively in the project related instructors, enhance the breadth and depth of research students participated in the study. This can avoid the situation of electrical students the knowledge structure quite sole can also solve the quantity of electrical our tutor on the problem of insufficient.

\section{TRAINING OF INNOVATION ABILITY OF RAILWAY ELECTRICAL ENGINEERING ACADEMIC GRADUATE}

For the training quality of electrical raises our students and improving the innovative ability of graduate students. Our school should establish comprehensive reform measures to ensure the quality of graduate students from several aspects. The academic graduate students as the main body, the teacher is leading the inquiry teaching, can effectively guide the students awareness of the problem, research found that the problem, heuristic graduate inherent curiosity, stimulate the potential of innovative thinking, the graduate students of knowledge from a passive acceptance of their transition to a positive exploration researchers found, and the creator (Liu Xianjun et al. 2008).

We change the class teaching situation and create the atmosphere of small classes in new environment. Teachers should be teaching and scientific research organically. The theoretical study and practice teaching organically combined. To check the actual effect of classroom research in practice, improve the teaching effect; training graduate students selflearning ability, the self spirit, handle the relationship between the independent study and cooperative innovation. Schools should strengthen supervision to ensure the curriculum, inquiry teaching quality. Construction on the school's strong academic atmosphere and let the postgraduate training thought.

Strengthening the construction of competition mechanism, the learning environment of race each other should be formed. A lot of the introduction of outstanding teachers from other schools, academic leaders invited to part-time professor at my school. Strengthen the teacher evaluation, the training of graduate students is not up to the requirement, shall cancel its qualification of teacher. Increasing capital input, should be provided more academic training opportunities for graduate students.

\section{CONCLUSIONS}

With the development of education in our country to accelerate the mass, postgraduate education has entered a new development. The original electric research single graduate cultivating model is no longer suitable for the need of development of social politics and economy in China. Therefore, at this stage of postgraduate education should pay attention to various abilities training. Although our country has been a graduate academic enrollment training mode are introduced, but also no one according to the present problems existing in the railway electrification to improve. Our school should consider from all aspects in order to solve the existing problems of graduate training.

\section{REFERENCES}

[1] Hong Yu, Zhong Binglin, Zhao Yingsheng \& Zhang Xiaoqian. 2012. The history, current issues and reform orientation of china's graduate education, China Higher Education Research, (7): 41-46.

[2] Liu Xianjun, Zhang Xiaoming \& Jia Yongtang. 2008. Research on the Mechanism of Talent Cultivation in Developed Country, Higher Engineering Education, (1): 71-80.

[3] Liu Yuenan. 2014. Research on existing problems and countermeasures of graduate education in Chinese universities, Jiangsu Higher Education, (2): 121-122.

[4] Mercedes \& Marzo. 2012. Analysis of the postgraduate cultivation method in the colleges with professional features. Educational Technology Research and Development, 10(2): 31-34.

[5] She Yuanfu \& Chen Jingchun. 2013. Cultivation of creative people and reform of graduate education system, Journal of Graduate Education, 13(2): 7-10.

[6] Xiuzhen Guo. 2012. How to solve the lack of two-way training graduate in accounting, Agricultural Accounting Chinese, 8(1): 14-16.

[7] Yu Shuangcheng, Zhang Ping \& Luo Hong. 2014. Analysis on formation mechanism of innovation ability for postgraduates, China Higher Medical Education, (2): 112-114.

[8] Zhu Min. 2014. Reflection and practice of propelling internationalization of research university, Higher Engineering Education Research, (1): 86-91. 